\title{
Limes Francolí, paisajes de frontera a ritmo sincopado.
}

\author{
Josep Maria Solé Gras ${ }^{1}$, Lluís Delclòs Alión , \\ Jordi Sardà Ferran ${ }^{3}$, Olivia Malafronte ${ }^{4}$
}

${ }^{123}$ Centre de Recerca Urbana del Camp (CRUC). Unidad Predepartamental de Arquitectura.

Escuela Técnica Superior de Arquitectura. Universitat Rovira i Virgili. Reus, Tarragona, España

${ }^{4}$ Dipartimento di Architettura, Design e Urbanistica. Università degli Studi di Sassari, Italia.

E-mail: 1josepmaria.sole@urv.cat, ${ }^{2} 1$ luis.delclos@gmail.com,

${ }^{3}$ sardaprim15@gmail.com, ${ }^{4}$ olivia.malafronte@e-campus.uab.cat

\begin{abstract}
Resumen. Espèces de espaces -Especies de espacios-, titulaba una de sus obras más celebradas el prolifico escritor francés Georges Perec. Su incisiva mirada, a menudo obsesiva, le permitía esbozar una descripción analítica de elevado rigor y detalle sobre los distintos objetos que componían sus espacios de cotidianeidad. Partiendo de la singularidad de cada uno, el autor pronto desvelaba las primeras relaciones entre los elementos estudiados y establecía, con ello, una propuesta de estructuración de los fragmentos en un todo que forzaba un obligado diálogo entre escalas. Cama, habitación, vivienda, edificio, manzana, barrio, ciudad, territorio o planeta como secuencias sobre las que articular una dicotomía clásica: particularidad o patrón.

Partiendo de este hilo argumental y con la misma intención metodológica del estudio pormenorizado de las partes y del todo, este trabajo se plantea destripar un lugar común como es el río Francoli de Tarragona. De caudal netamente irregular y trazo indeciso, sus aguas riegan un rosario de situaciones territoriales complejas y usos contradictorios. Los frágiles humedales de la cabecera preceden el paso angosto cuya fuerza motriz alimenta malolientes papeleras, la arquitectura languidece en el llano interior hasta que la petroquimica humeante impera y divide en su tramo central. Finalmente, la ciudad, en su anhelado encuentro con el mar, canaliza y retuerce su curso asestándole una última estocada. Lugar de pocos puentes donde los grandes déficits históricos y riesgos patentes conviven -o malviven- con el enorme potencial de su transformación. Fijar la mirada, describir y articular para descubrir, medir y ponderar
\end{abstract}

Palabras clave: Espacio de Frontera, Río Francolí, vulnerabilidad social, riesgo antrópico, territorio fragmentado

\section{Declaración de intenciones}

Esta investigación pretende presentar el río Francolí como cuerpo de estudio. Su escaso recorrido, con un renqueante y torturado curso, sirve de principal hilo argumental para, a través de la suma de sus partes, reconocer una imprecisa y evocadora amalgama de valores, potenciales, retos y contradicciones que, como si de una colección de objetos e intereses inconexos se tratara, se articulan a lo largo de su trazado.
El repertorio de situaciones urbanas y territoriales que lo acompaña es rico y variado. Así pues, se pretende explorar sus lugares propios y ritmos de transformación, replantear la disposición de las piezas que lo componen y permiten o niegan su paso, cuestionar sus espacios intermedios, medir sus intersticios, comprender la vocación y uso cotidiano de sus límites, identificar los espacios de abandono, los territorios residuales y, sobre todo, descubrir los lugares de oportunidad. Esta colección de miradas queridamente 
variadas ensaya métodos diversos que aspiran a convertirse en el principal argumento de esta investigación: alcanzar la toma de consciencia del todo para la revalorización paisajística, ecológica, perceptiva y productiva de un río cuya reciente fragilidad no es sino un reflejo de la progresiva pérdida de peso estratégico territorial experimentada en las últimas décadas.

A continuación, se presenta el estado de la cuestión de una investigación incipiente. Una primera mirada que debería permitir dar orden y estructura a lo que se ha hecho, lo que se está haciendo y, sobre todo, apuntar a lo que está por hacer. El resultado abre temáticas más que condensarlas, insinúa posibles caminos más que acotarlos y se ubica en el campo de la especulación objetiva, la promesa latente, la hipótesis variable, la heterogeneidad temática y la variedad metodológica con el objetivo final de obtener una mirada compleja, poliédrica e inclusiva sobre el río en su conjunto (Imagen 1)

\section{Métodos parciales}

Con la voluntad de recoser el mapa de fragmentos, enlazar los ámbitos de transición, desvelar los vectores de transformación evolutiva, recomponer las miradas parciales y revelar los hilos de una memoria menguante, este estudio se quiere servir de varios métodos de carácter analítico. Algunos de ellos, con un enfoque deliberadamente parcial, a modo de prueba. Ensayo y error como paso esencial a la aplicación de una metodología completa y sistemática de análisis territorial a partir de la secuencia de preguntas, miradas y propuestas

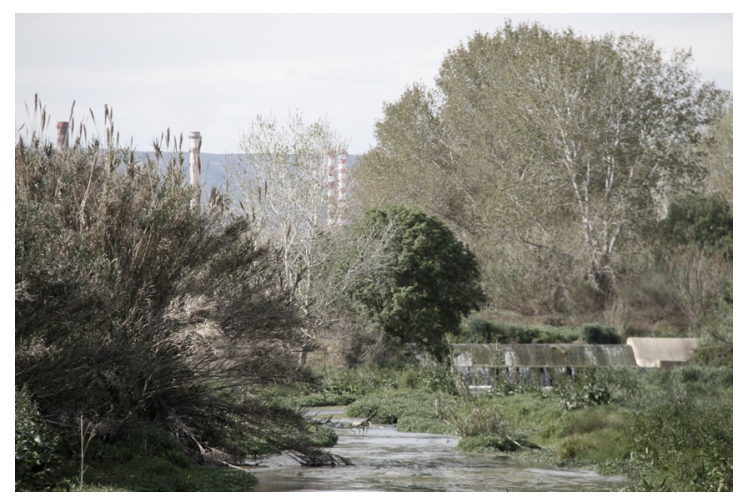

Fig. 1. Estratos superpuestos (Solé, 2019) para una cuenca fluvial cuya complejidad no permite simplificación alguna. Uno a uno, estos serían:

La cartografía, como herramienta de contextualización, medida y estructura. Ya sea a partir de la recopilación y análisis de los mapas históricos o de la elaboración de cartografías de carácter propio, éstas pueden ser de ámbito generalista o cuestionar lugares precisos cuya particularidad obliga a una exploración detallada en busca de la especificidad vs el patrón. En este sentido, un ejercicio de constante diálogo entre el fragmento y el todo se convierte en una de las principales claves de lectura de este territorio y de la construcción de su imaginario.

Con ello, sus lógicas de transformación reciente y la progresiva fragmentación derivada de unos usos a menudo incompatibles entre ellos han dibujado un nuevo panorama en el que impera el segmento, la mancha y el límite sobre la frágil unidad biofísica de su cuenca. En este sentido, si bien algunas de las realidades territoriales inventariadas se apoyan sobre las estructuras geográficas subyacentes, otras, en cambio, han introducido nuevas variables que, en la mayoría de los casos, se han traducido en espacios de aparente contradicción, disfunción o duda permanente. Con ello, si bien es cierto que algunos estudios o documentos normativos recientes han apuntado una cierta cohesión de los valores paisajísticos de algunos de estos ámbitos fluviales -véase el Catàleg del Paisatge del Camp de Tarragona (2012) o La vida al riu Francolí. Els humans i els sistemes aquàtics de la misma URV (2014)-, la voluntad de la selección cartográfica aquí presentada ha sido precisamente cuestionar estas unidades de paisaje y enfatizar, a la vez, ellos distintos grados de impacto antrópico como definidor del ámbito estudiado.

La fotografía -y otras variantes de carácter audiovisual como el video o el fotomontajeretienen parte del imaginario y condensan relato y memoria de un lugar. En este sentido, la imagen se ha erigido, en esta parte inicial del estudio sobre el río Francolí, como medio destacado tanto por su condición retentiva de instantes fundamentales que estructuran la percepción como por su capacidad de establecer un marco de referencia visual, un 


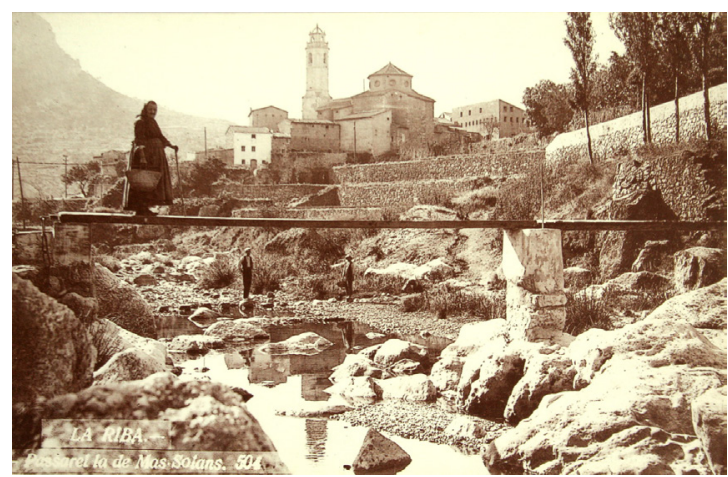

Fig. 2. Paso de la Riba (Fuente: colección de postales J. Sardà, 2019)

contexto, sobre el que identificar elementos significativos, desvelar jerarquías y sistemas de interrelaciones e insinuar estructuras de complementariedades, superposiciones o, por el contrario, reiteraciones y contradicciones. Entendemos, en este sentido, que su capacidad sintética permite reconstruir la imagen de un lugar perdido y, a partir del reconocimiento de sus límites, recomponer su rostro completo.

La imagen 2 muestra una relación íntima, de uso cotidiano y escala cercana entre los espacios urbanos y fluviales. En este caso, en el paso de la Riba. (Imagen 2)

La entrevista, por último, evoca y focaliza. Una una y a modo de conversación estructurada entorno a un lugar conocido, las vivencias pasadas, las experiencias de la cotidianeidad presente $\mathrm{o}$, incluso, los anhelos de un futuro incierto revelan vínculos emocionales entre el residente del territorio Francolí y el entorno fluvial sobre el que habita. Aportan, en términos metodológicos, el vector cualitativo y los datos referenciales de unas biografías ligadas a la suerte del río. De este modo, tras 22 entrevistas a residentes del Serrallo -el barrio más cercano a la desembocadura-, han aflorado diferentes verbos como pescar, jugar, convivir, o cuidar que remiten a un pasado de relación íntima con el Francolí y sus bordes. Otras conversaciones mantenidas con los usuarios del reciente Parque fluvial o residentes de los llamados barrios de Ponent -situados al lado opuesto de la ciudad de Tarragona- han revelado, por su parte, sustantivos como fragmentación, lejanía o abandono evidenciando, pese a la cercanía física de estos tejidos con el río, un elevado déficit de conectividad.
En cualquier caso, esta primera ronda de encuentro con estos actores ha confirmado la necesidad de incorporar una componente metodológica que sistematice la toma de datos perceptivos y pondere las opiniones sobre este espacio de intereses encontrados. Por ello, actualmente se están diseñando una serie de entrevistas grupales y encuestas individualizadas que posibiliten la normalización de las respuestas y la ampliación de la muestra al resto de ámbitos fluviales. Las temáticas, de nuevo, incidirán sobre conceptos como la memoria, el riesgo y conflicto, los usos de los espacios, sus relaciones y, por último, el potencial de reapropiación del espacio-río.

\section{Matices de enfoque}

En paralelo a la entrada multimétodo a partir del uso de diversas técnicas analíticas yuxtapuestas, se plantea una segunda derivada temporal y un refinamiento geográfico. En este sentido, si los métodos pueden servir para ponderar y comparar, la aproximación temática y geográfica nos debería permitir filtrar y seleccionar ámbitos paisajísticamente coherentes cuyas características formales y problemáticas o usos sean compartidas posibilitando, de este modo, la correlación entre variables de estudio.

De este modo, en términos geográficos, los ámbitos resultantes identificados serían, en el sentido descendiente del curso fluvial: el nacimiento, el paso angosto de la Riba, el llano de matriz agrícola, el recinto de la Petroquímica, la huerta, el parque urbano entre ciudad e industria $\mathrm{y}$, por último, la torturada operación de desembocadura insertada en el complejo portuario. A título temporal, en cambio, las cuestiones planteadas han pivotado entre la construcción colectiva del recuerdo, la identificación de las vicisitudes presentes $\mathrm{y}$, a modo conclusivo, la proyección de un escenario de futuro.

\section{Aprendiendo del pasado}

El olvido que seremos, titulaba, de manera evocadora, una de sus fantásticas novelas Héctor Abad Faciolince. En ella, reflexionaba sobre los espacios de una memoria que se 
debatía entre la serenidad del recuerdo de una infancia feliz y cultivada y la ansiedad de convivir con el miedo aterrador provocado por la amenaza constante de vivir en la turbulenta Medellín narcotraficada. El río Francolí, en cierto modo, tiene algo de ello y los habitantes de la parte alta de su cuenca conviven al ritmo pausado de una agricultura renqueante, de viejos tractores y caminos polvorientos que antaño fueron símbolo y seña de la totalidad del lecho fluvial. La llegada de la gran industria petroquímica, no obstante, supuso nuevas gentes y barrios, otros ritmos de movilidad y la profusión de nuevas infraestructuras que significó una fractura funcional y territorial que permanece plenamente vigente.

Tal cambio inauguró una época de convivencia obligada con un riesgo cuya cotidianeidad no ha hecho sino normalizarlo convirtiendo a aquellos que habitamos en el entorno Francolí en seres de aparente amnesia. Los hechos evidencian el diagnóstico de una amenaza que acecha y 1994 se impone como fecha de referencia traumática. Es un número que pesa por encima del resto en la memoria de muchos. Fue el año en que, en cuestión de horas, aquel río que apenas es capaz de garantizar su caudal en las épocas estivales desbordó e inundó por doquier recordando, mediante el drama de numerosos daños materiales, la fuerza dominante del territorio y el trazo de un curso natural inocentemente encauzado. Las imágenes retransmitidas en vivo de los puentes caídos y los bordes borrados por una gran mancha de agua turbia y embravecida que no cesaba de crecer hasta niveles nunca registrados con anterioridad, aumentaban su dramatismo mediático con los efectos de aquella colección de árboles arrancados y coches arrastrados. No obstante, si bien la contundencia de unos efectos dramáticos pudiera predecir un cambio radical en el enfoque de la relación territorial con el río, nada más alejado de la realidad.

De hecho, las retinas de los habitantes, demasiado acostumbradas a la exposición continuada al riesgo antrópico, vieron como las transformaciones urbanas del territorio mantenían las pautas de segregación y explotación de este entorno frágil con una suerte de amnesia autoimpuesta. Pongamos, a modo de ejemplo de dicha actitud de querida amnesia, el planeamiento de la ciudad de Tarragona. Su POUM (Plan de Ordenación Urbanística Municipal) vigente contempla los suelos de la llamada Horta Gran -un terreno llano, de gran fertilidad atrapado entre polígonos de viviendas, industrias químicas y nudos infraestructurales- como ámbito urbanizable. Dicha vocación urbanística impuesta sobre un espacio de elevada sensibilidad, si bien puede responder a un argumento de continuidad urbana, conlleva simultáneamente un riesgo potencial de repetición, o incluso aumento, del desastre natural todavía reciente de las inundaciones del 94. No en vano, la zona es declarada por la ACA (Agencia Catalana del Agua), por su estructura morfológica y su geología, como zona inundable en los periodos de retorno de 50, $100 \mathrm{y}$, por supuesto, 500 años. Dicha contradicción aparente se ve reforzada, además, por su localización en el ámbito más bajo del curso del río, en el embudo final que forman el barrio pesquero del Serrallo cercano al puerto y el Polígono Industrial Francolí, prácticamente en su desembocadura. Esta configuración, agravada por el repentino giro impuesto al río antes de su llegada final al mar con la intención evitar la descarga masiva y continuada de sedimentos sobre el ámbito portuario, fue uno de los factores detonantes de los efectos causados por las inundaciones de 1994 (véase Imagen 3).

La solución adoptada, en aquel entonces, pasó por construir muros y taludes perimetrales, a modo de caja, que dieron una solución temporal a la problemática del riesgo si bien, como derivada colateral, enfatizaron la segregación funcional y reforzaron el déficit de conectividad del río y sus contornos urbanos. En otras palabras, proteger a costa de aislar. Una estrategia de urgencia que cuestiona el concepto de la continuidad y simplifica la ecuación de los encuentros en aras a una mitigación universal del riesgo que contrasta con la apuesta por urbanizar ámbitos como la Horta Gran y hacen aflorar preguntas como ison el muro y el nuevo desarrollo urbano planteado soluciones amnésicas e inconscientes o, por el contrario, fórmulas que pueden ayudar a compatibilizar riesgo y sutura territorial? Está por ver. Cabrá, a partir de aquí, fijar la atención en el posible replanteo de modelos alternativos que, desde 

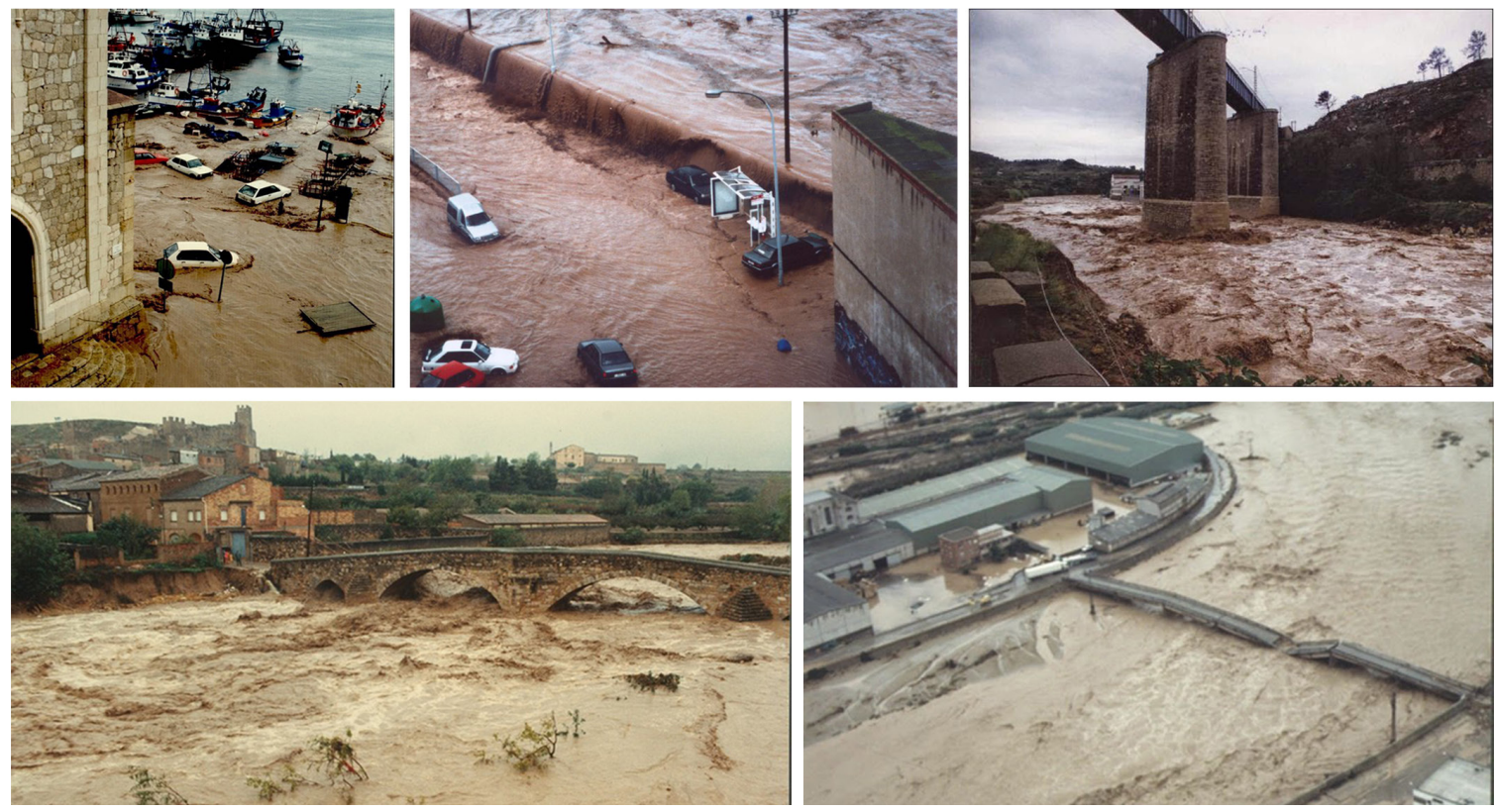

Fig. 3. Instantáneas de un desastre. (Extraídas de La riuada de 1994 (Lahoz, 2014))

el rigor, dibujen escenarios de compatibilidad que luchen contra el olvido latente. (Imagen 3)

\section{Hoy por hoy}

Estirando el hilo argumental que cuestiona la correlación entre la condición física del espacio Francolí y la carga perceptiva que la acompaña, el estudio detallado del momento actual quiere centrar su atención en generar una taxonomía detallada de los elementos que propician, generan o facilitan la fragmentación territorial sobre la que se apoya argumentalmente la imagen de segregación reiterada. En este sentido, se pretende listar, describir y reparar en la identificación y caracterización de los conflictos, las contradicciones, los muros que lo separan y protegen, los escasos accesos y rampas, los pocos pero grandes puentes que lo cruzan, los omnipresentes recintos que lo bordean y separan, la frágil red de caminos que aparecen y desaparecen, los lugares de cultivo, los puntos altos dominantes y las áreas recurrentemente inundadas, los paisajes sonoros y de olores, las especies que lo habitan. Se trata, en definitiva, de establecer una radiografía detallada del río y su entorno de influencia a partir de la sospecha de un plano, la fotografía de un lugar, la determinación de sus límites $\mathrm{y}$ condicionantes y el cuestionamiento de sus percepciones como principales herramientas para reconocer las relaciones entre las partes a la vez que revelar espacios de oportunidad sobre ámbitos de contradicción o estructuras subyacentes, a la espera de revertir las fuerzas impuestas sobre la frágil y olvidada condición fluvial de su matriz biofísica.

Con la voluntad de entender las transformaciones, sus ritmos $\mathrm{y}$, sobre todo, sus efectos, este estudio, hasta el momento, ha tratado de poner en diálogo las dinámicas de lo que fue, con lo que es y puede ser el río. Mirar atrás para determinar las condiciones subyacentes que se han mantenido, los vectores que se han impuesto y el reequilibrio constante entre las dinámicas de la industrialización, el desarrollo urbano, la explotación agrícola o el mito del bosque virgen. En este sentido, en aras de posicionar en relación con el vector temporal algunos de los episodios de transformación más relevantes para este territorio. Para ello, se ha elaborado la matriz (véase Imagen 4) que muestra la evolución territorial a partir de 6 episodios, siendo, por orden cronológico, 1946, 1956, 1983, 1996, 2006 y 2016. Estas fechas corresponden los vuelos disponibles en el repositorio cartográfico del Institut Cartogràfic de Catalunya para este ámbito territorial. Como resultado, se observa, en su estadio inicial -en 1946- un claro predominio del uso agrícola 


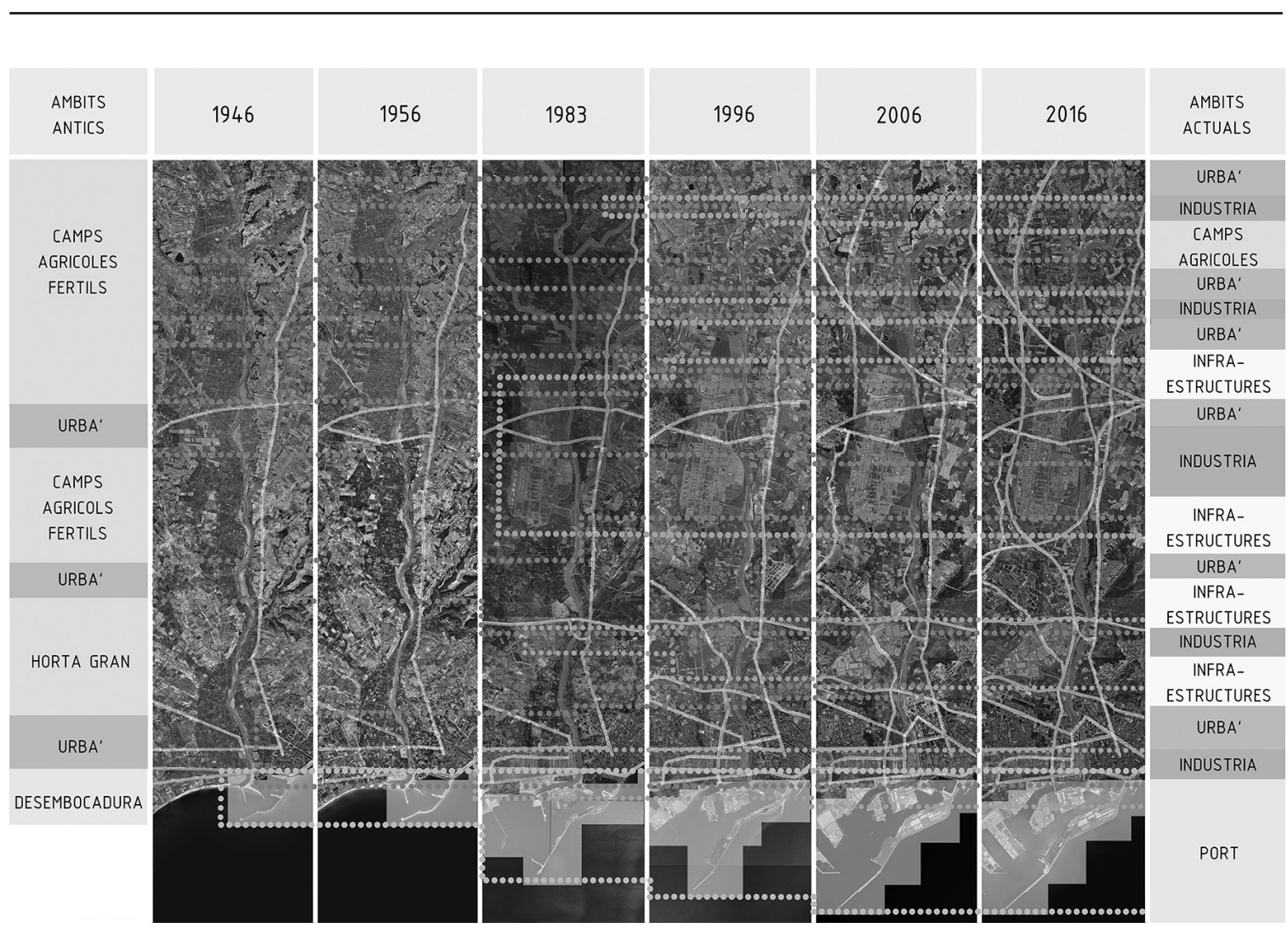

Fig. 4. Tiempos y fragmentación de los tramos urbanos del Francolí (Malafronte con CRUC, 2019)

con alguna presencia urbana puntuando y reforzando los bordes del río. A medida que avanzan las décadas, la aparición progresiva de nuevas líneas horizontales (infraestructuras) y grandes manchas (polígonos industriales y residenciales) salpican el ámbito fluvial aportando, para el estadio más reciente -2016la imagen de un río de curso fragmentado y ritmo sincopado, una colección de nuevas fronteras y límites que cortan pasos y caminos, dividen lados, dibujan recintos y separan fragmentos potenciando el repertorio de nuevas situaciones de letargo permanente. (Imagen 4)

A su vez, siguiendo con la lógica de escrutinio, la Imagen 5 muestra la comparación de la estructura de la propiedad de los principales recintos creados durante esta época, en su dos momento inicial y final. En ella, se observan cuestiones tan significativas como la construcción de nuevo suelo ganado al mar, la modificación del trazado del río en su llegada al puerto o el paso precipitado de terrenos de estructura agrícola de grano menor a piezas de gran superficie, monofuncionales y, en muchas ocasiones, de propiedad única. Más allá de su evidente impacto sobre la estructura territorial, estas transformaciones radicales supusieron cambios de gran calado sobre las propias dinámicas dominantes del ámbito Francolí, así como de su percepción. (Imagen 5)

Dando cuenta de la voluntad de construir un inventario de los límites que permita cuantificar y clasificar el porqué de ciertas percepciones, este estudio incorpora el dibujo y fotografiado de los distintos elementos y dispositivos construidos en favor de la accesibilidad o, por el contrario, de la protección. En otras palabras, este estudio listará puentes, caminos, muros, taludes y terraplenes, desmontes, miradores, orillas, vallas, molinos o masos, ruinas, polígonos o explanadas residuales que acompañan el río y definen sus líneas o ámbitos de frontera. Des su conocimiento preciso dependerá la capacidad de propuestas alternativas.

En este sentido, la imagen 6 recoge la descripción gráfica, a modo de testigo, de algunos elementos tales como infraestructuras, límites o pasos. $\mathrm{Su}$ registro, filtrado y estructurado, permite responder de manera clarificadora a la doble hipótesis planteada inicialmente: 


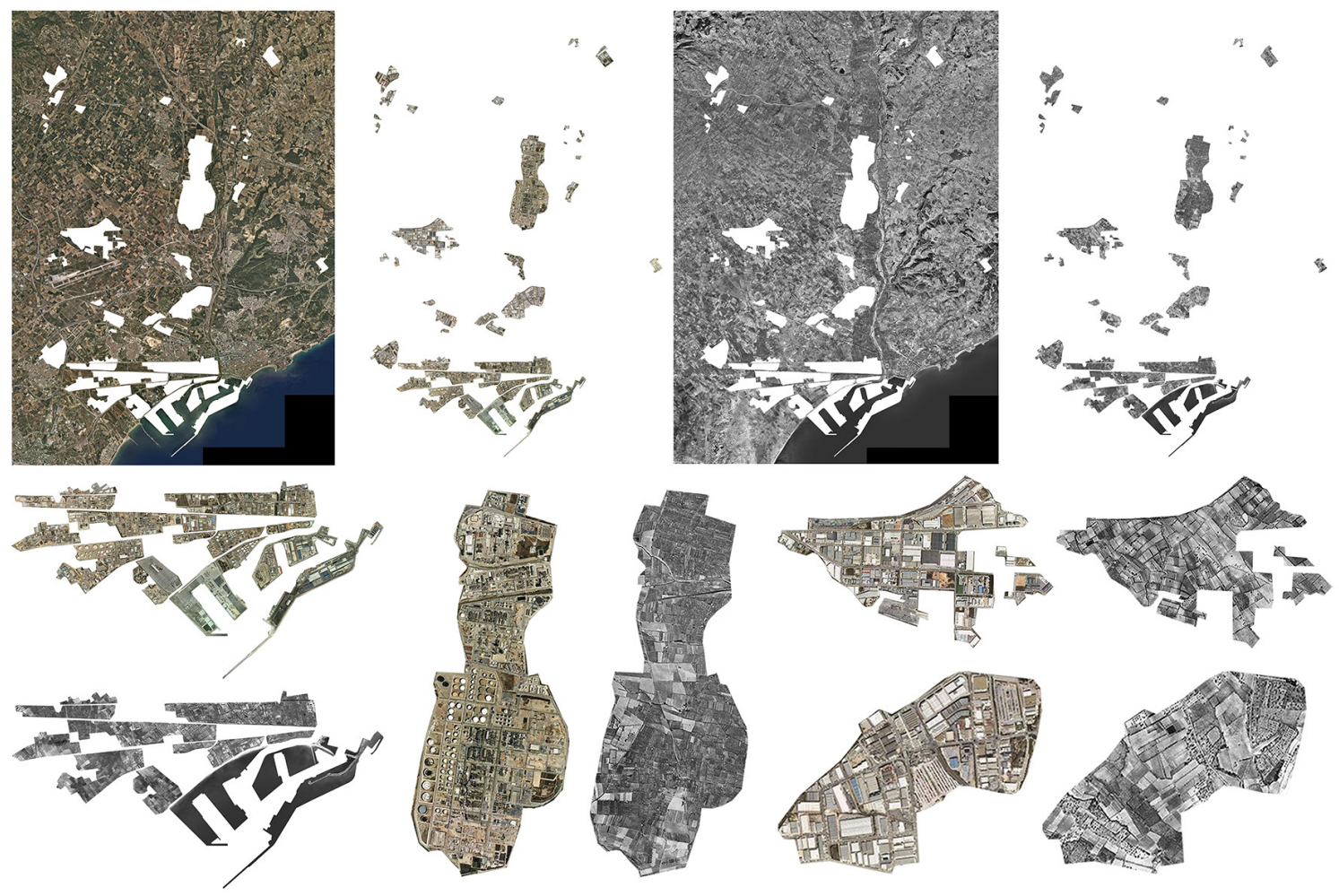

Fig. 5. Tiempo y recintos (Malafronte con CRUC, 2019)

- la mera comprensión del lugar descubre un orden de oportunidades subyacente.

- la consideración residual del río y su traducción a una percepción de lugar sin significativo propio. (Imagen 6)

Las imágenes 7 y 8 , por su parte, plantean el primer paso de identificación de ámbitos de conflicto y oportunidad cartografiando, con ello, un repositorio de espacios territorialmente estratégicos en la recuperación del ámbito Francolí como lugar de referencia. (Imagen 7 y 8 )

\section{El dibujo de un rostro completo para la construcción de un mañana}

Si bien se estima que los primeros pobladores del territorio Francolí se asentaron en su cuenca hace más de 100.000 años, este río sigue siendo de los menos estudiados de Europa. De hecho, ni siquiera se conoce el origen del nombre y todavía hoy sigue abierta la discusión sobre si su toponimia deriva del latín, de la lengua franca, árabe o germánica. Uno de los argumentos que podrían explicar dicha anomalía podría ser la ausencia continuada de estudios universitarios en la región. En este sentido, la presencia relativamente reciente de la Universidad Rovira i Virgili ha empezado a dar sus primeros frutos en términos de la elaboración de distintos análisis -puntuales y continuados- de las calidades del aire, el agua o el estado de madurez de la biodiversidad. En esta misma línea argumental, dicho trabajo de investigación pretende colaborar a través del dibujo completo del territorio Francolí, de la elaboración de la serie de cartografías que identifiquen el rostro de este ámbito de estudio tan particular que, en palabras de los mismos encuestados, resulta ser "un río de todos y de nadie".

De este modo, se descubre una cuenca en forma de pera que incluye 6 comarcas y tiene una superficie de $853 \mathrm{~km} 2$ y un perímetro de 225 kilómetros. Su punto más alto es el Tossal de la Baltasana, un promontorio de 1.202 metros sobre el nivel del mar que pertenece a la sierra de Prades. Su curso, des de su origen en la Font Major de la Espluga de Francolí, tiene un recorrido de $54 \mathrm{~km}$ de 

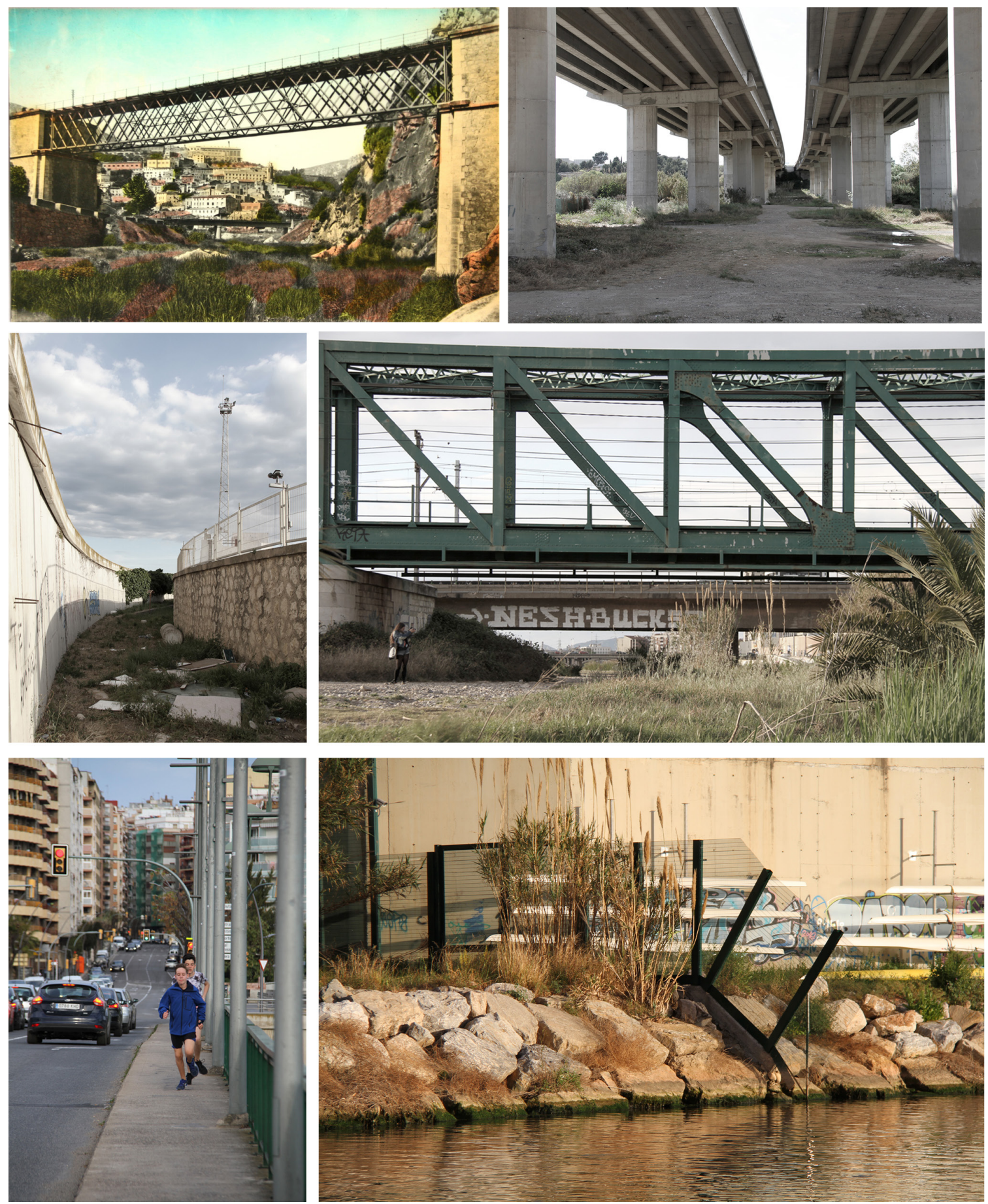

Fig. 6. Registro de pasos. (Solé, 2019) 


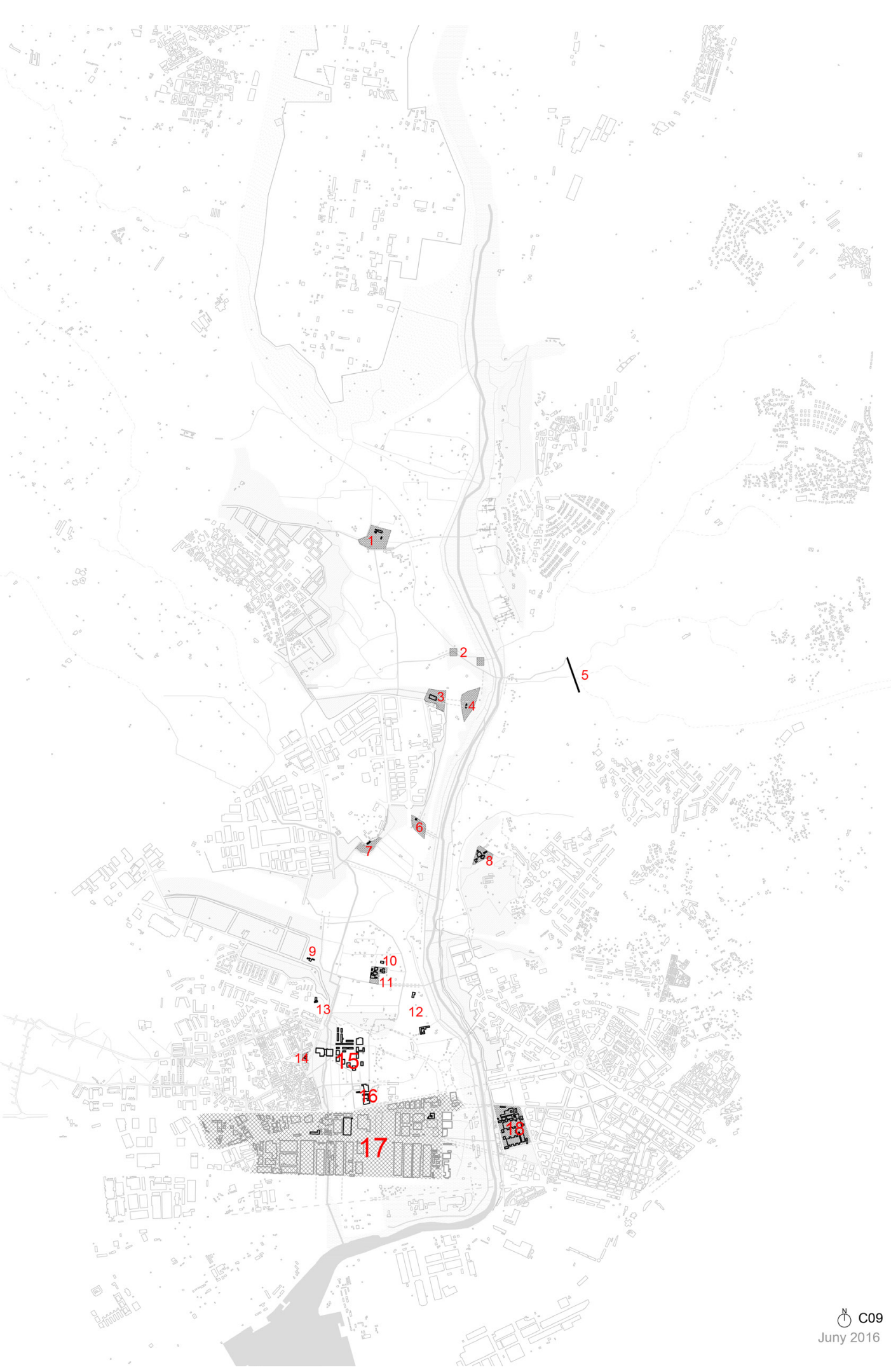

Fig. 7. Cartografiado de potencialidades, aprovechamiento y transformación. (PFC, Delclòs-Alió, 2016) 
1. Mausoleu de Centcelles. Espai d'interés
historic $i$ arqueologgic visitable. Data d'época romana en els seus inicis s'si croben afegin
importants d'êpoques més recents. En bon estat

2. Molinet de Mas Mascaró. Restes en ruina.

3. Mas de Mascaró Ruines catalogades.

4. Mas de la Xeca o d'Adseries Ruines
dinterés per la possible pertanyenģa al Mas de Mascaro.

5. Pont del Diable Monument arqueologic

6. Boca de la Mina Protectora i Moli de l'Horta La mina està en funcionament i és
bàsica per a l'Horta El moli està en ruines bascle per a liona. El moli esta en ruines i

7. Ruinnes Vilatge dels Mongons. Ruines catalogades en mal estat.

8. Masia-restaurant Les Fonts de Can Sala

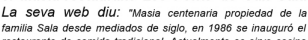

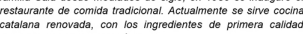
9. Mas de Mansió. Mas en funcionament

10. Mas del Ros. Mas en funcionament, al cor

11. Hipica. Ús compatible per la seva singularitat el Tentorn. Es tracta de donar priontitat als usos agricoles, perto puntualment
altres usos at mig de lhorta poden
dinamitzar a 12. Mas de Pinyolet i Mas de Ribot. Masos en
funcionament funcionament

13. Mas de Carreter. Mas en funcionament

14. Mas de la Torreforta. Ediffi origen del urbana l'ús actual (Institut municpal de Serveis Socials públics) sembla adequ

15. Riuclar. Barri a tocar del torrent homonim caldria consolidar-lo en espais compatibles de
la zona i millorar les condicions d'alguns dels

consolidar-lo en espais compatibles de la zona habitatges.

17. Poligon Industrial Francoli Principal
operacio d'aorofitament i transformació. operació d'aprofitament i transformació.
Procurar aconseguir un teixit mixt que mantigui

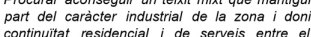
continuitat residencial i de
centre iels barris de ponent.

18. La Tabacalera Edifici de grans dimensions
que interessa molt a la ciutat recuperar per
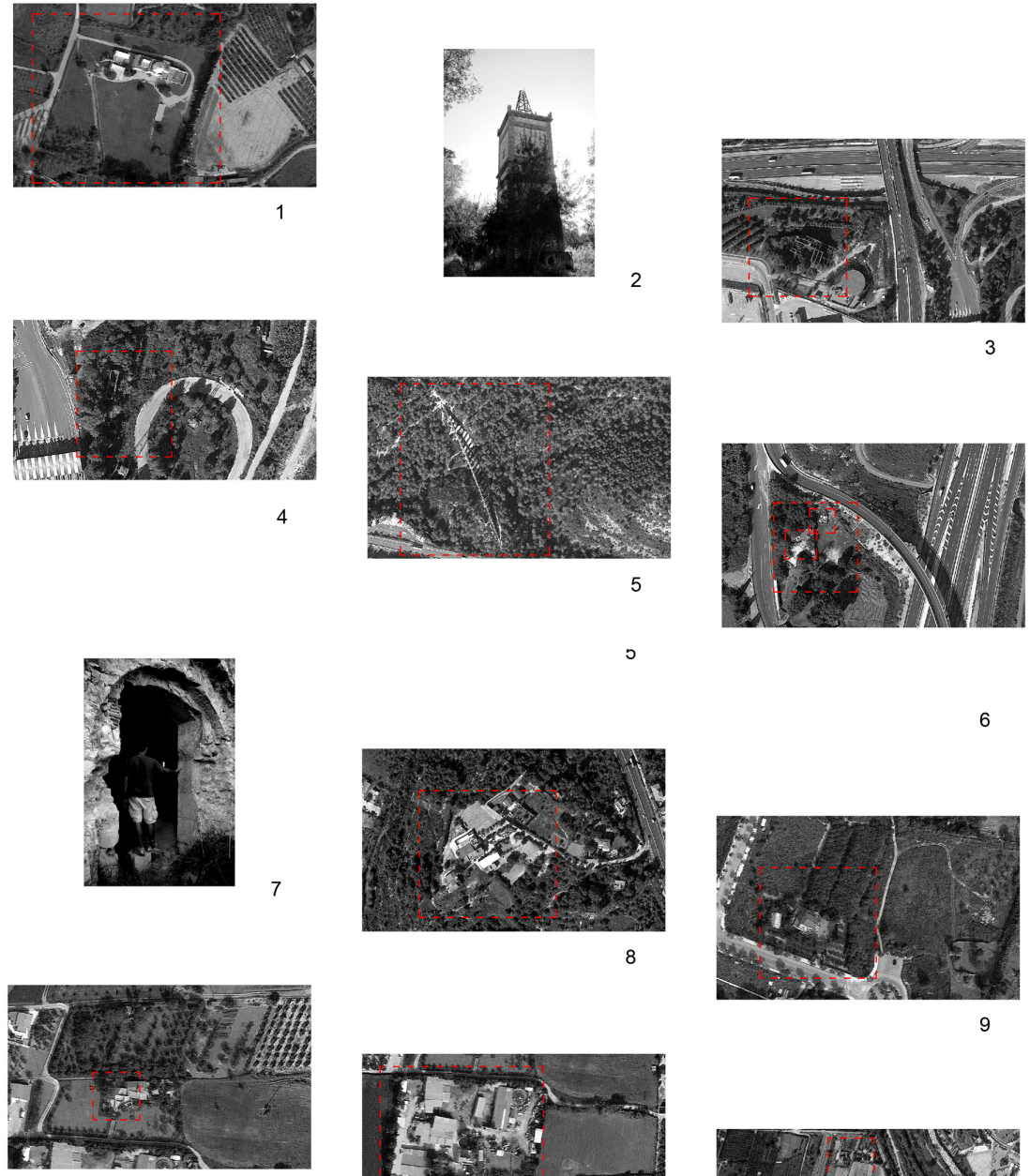

10
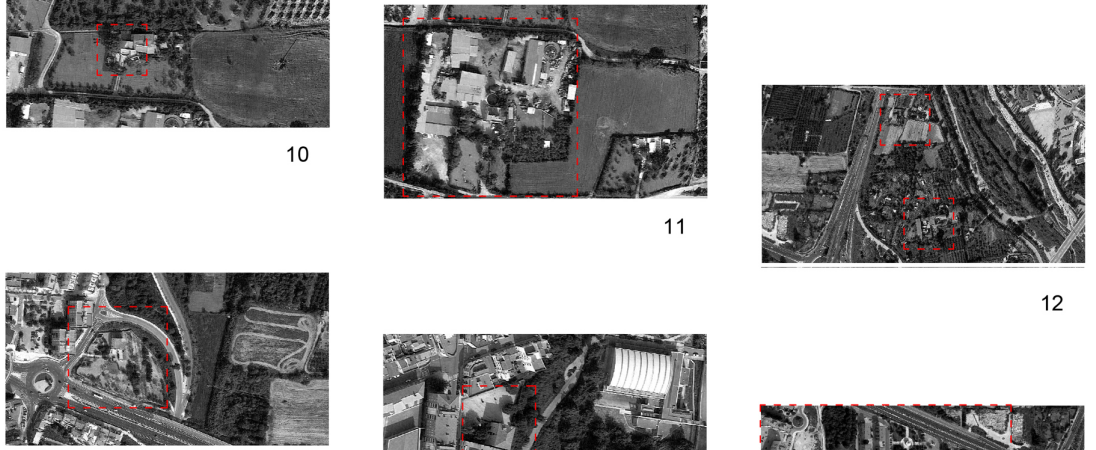

13

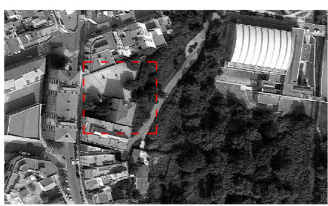

14
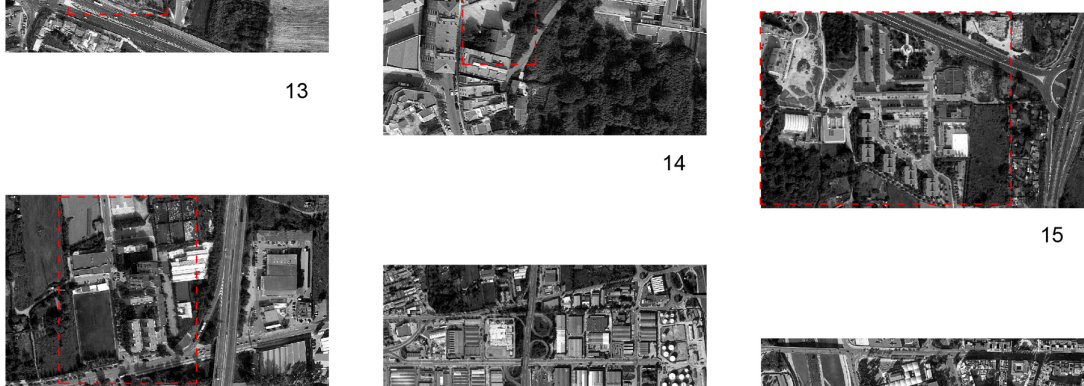

16

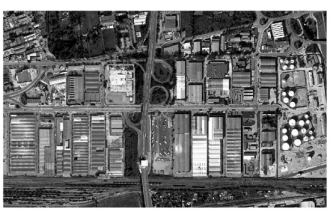

17

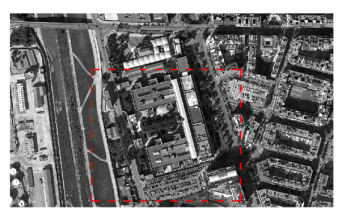

18

Fig. 8. Catalogación de potencialidades, aprovechamiento y transformación. (PFC, Delclòs-Alió, 2016) 


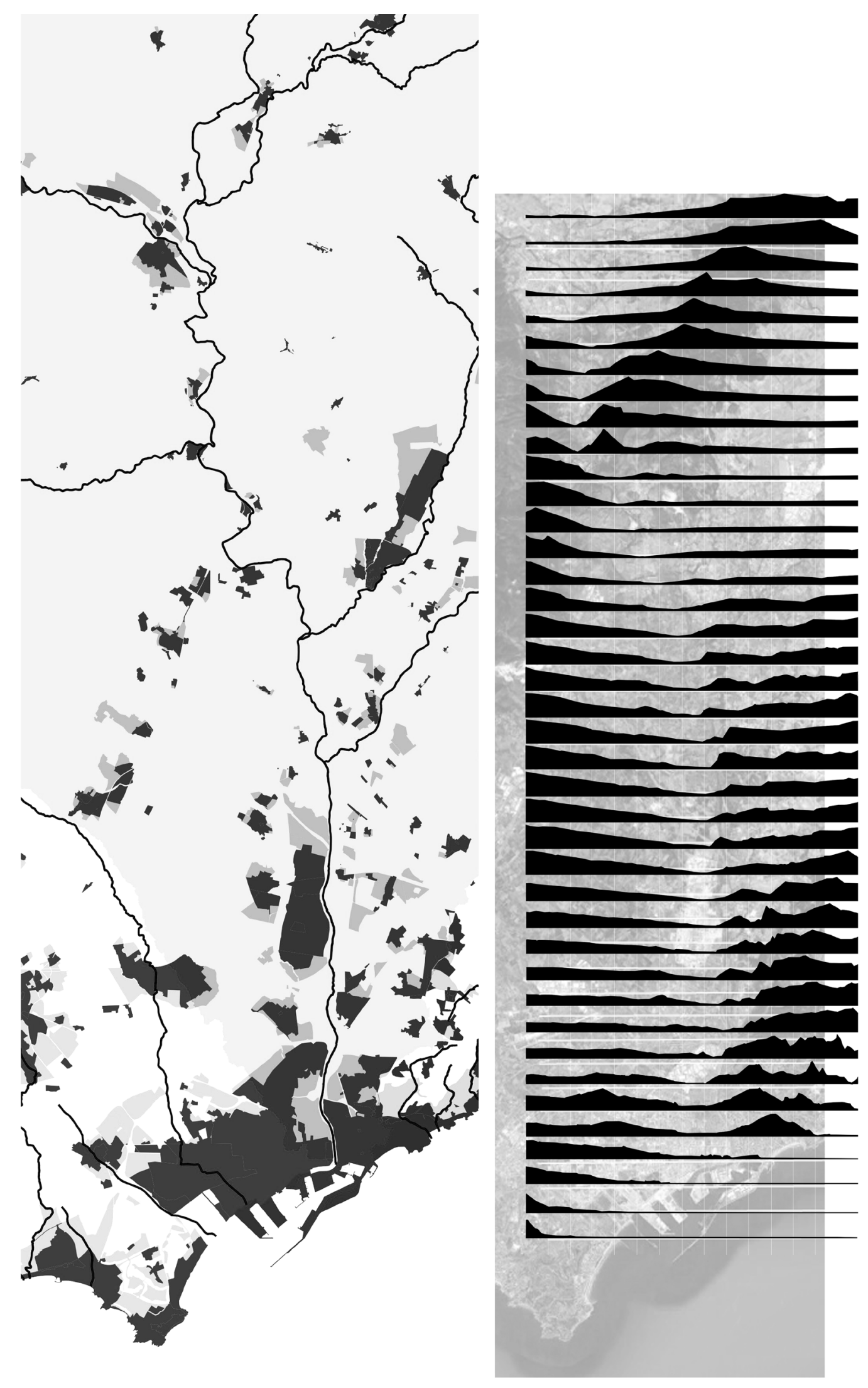

Fig. 9. Miradas sobre la cuenca del Francolí. Curso-urbanización y relieve. (Elaboración propia, 2019) 
longitud hasta el mar recogiendo numerosos afluentes y atravesando hasta 40 puentes $\mathrm{y}$ 12 municipios. Un ámbito de oportunidades, donde la secuencia de situaciones y capítulos se combina y yuxtapone mediante estructuras de elevada complejidad. Desgranarlas primero para recomponerlas después ha resultado ser un primer paso revelador en la descubierta de nuevos retos, oportunidades y valores sobre los cuales recomponer las progresivas miradas a un río cuya vocación debería sentirse apelada a pasar de frontera a corredor mediante un obligado giro de coordenadas que, de la imperante horizontalidad de las infraestructuras dominantes -paralelas al mar- dé paso a un territorio que reconozca el potencial de sus directrices verticales -sus aguas- como elementos de refundación ecológica y reequilibrio sistémico. (Imagen 9)

\section{Agradecimientos}

La investigación de esta ponencia se ha financiado mediante el Ministerio Español de Ciencia, Innovación y Universidades a través de su proyecto de investigación CHORA (CSO2017-82411-P) y AEI/FEDER,UE y por el Departamento de Investigación y Universidades del Gobierno Catalán por medio del grupo 2017SGR22.

\section{Referencias}

Aguilar, F. 2008. El Francolí. Barcelona : Viena.

AA.VV 2012 Catàleg de Paisatge. El Camp de Tarragona. Barcelona: Generalitat de Catalunya, Departament de Territori i Sostenibilitat

De Ortueta Hilberath, E. 2006. Tarragona, el camí cap a la Modernitat. Urbanisme i arquitectura. Barcelona: Lunwerg.

GEPEC, Lliga per a la Defensa del Patrimoni Natural, 1999. El Francolí, fins arran de mar en Monografies d'espais naturals, núm. 1. Barcelona: Depana.

Lahoz, R. 2014. La Riuada de 1994. Tarragona: Arola Editors

Ortiz, J. Meseburger, G. 2014. La vida al riu Francolí. Els humans i els sistemes aquàtics. Tarragona: Publicacions URV.
Solà-Morales i Rubió, Manuel. 2009. "Un camp de coses (els buits de la metròpolis)". Tarragona: Revista AT 19 (1): 3 p. 